\title{
The Influence of Matrix Content on the Properties of Friction Material
}

\author{
Qingwen Qu, Tianke Sun, Shaoqing Wang, Hongjuan Yu \\ School of Mechanical Engineering, Shandong University of Technology, Zibo, China \\ Email: quqingwen@sdut.edu.cn
}

Received January 16, 2012; revised February 14, 2012; accepted February 28, 2012

\begin{abstract}
The effects of modified inorganic water-based matrix content on the properties of friction material was studied in the present paper, the regular pattern of the influence of friction material's friction coefficient and wear rate on matrix content have been got. It provides technical support for the study of cold forming friction material, and provides the basis for the development and production of the green pollution-free friction material.
\end{abstract}

Keywords: Matrix; Friction Material; Coefficient of Friction; Wear Rate

\section{Introduction}

According to the processing temperature, the productive technology of automotive friction material distinction can be divided into three categories: hot-press process, cold-press process and warm-press process. The most widely used technology is hot-press forming process. And it is still a major productive technology of friction material for the international manufacturer. Its principle is that melt the blank and flow to fill the cavity by heating and pressing in the process of forming, and make the cure reaction of resin happened. Compared with the hotpress forming process, cold-press forming process [1] is a method which forming under $10^{\circ} \mathrm{C}-100^{\circ} \mathrm{C}$. Warmpress process is a processing method of friction material that the forming compound form under definite temperature $\left(100^{\circ} \mathrm{C}-130^{\circ} \mathrm{C}\right)$ and pressure. The friction material which manufactured with cold-press forming process has been widely used in automotive original supporting in foreign countries due to its excellent frictional property, low density, high porosity, low noise, low cost, easy to automated production, etc. Literature [2,3] puts forward to use the dry process, matrix resin chooses the phenolic resin produced by suspension polymerization, its formula design uses the material stack effects to stack the material to shape under pressure. The clutch friction material which prepared with the method of cold-press by Y. J. Zhang [4] has the high, controllable porosity and low hardness, good friction and wear properties, and in the high temperature frictional condition it has excellent antideclining property; The automotive friction material which prepared with the method of cold-press forming at room temperature by R. J. Lu [5], uses the two-component liquid resin as the binder and without using fixture in the post-processing. It has good friction and wear properties, low noise, etc. Y. Yu [6] studied the warm-press for preparing the brake friction material, and the prepared material has stable friction coefficient, good anti-heat fading capability, low wear, low hardness and low noise probability; T. Zhu [7] prepared a kind of friction material which has high impact strength and good friction and wear properties with the method of warm-press by using three-component modified resin and hybrid fiber as raw material; The drum brake friction material which prepared with the method of warm-press by J. F. Wei [8], uses the cashew nut oil melamine modified liquid phenolic resin as the binder. It has good friction and wear properties and moderate porosity.

Nowadays, the energy conservation and environmental protection is the social mainstream, and also is the enterprise and civil important consciousness. This study in the knowledge foundation, researched on the low temperature cementing cold forming formula [9] and the forming process, then formed the energy saving, low consumption and pollution-free product. The key of the low temperature cementing cold forming is the choice of matrix material and the modification. Binder matrix can not only make the components of friction material bond together organically, but also ensure the necessary friction properties of material. Different content and species of matrix has an important influence on the friction and wear properties, mechanical properties and thermal properties. This paper uses a new inorganic water-based binder, and mainly investigates the influence of matrix content on the friction material characteristics. 


\section{Experimental Design}

Matrix is the main components for determining processing technology, this study uses modified liquid binder as the matrix material. The binder can be dried and curing into hard gel structure at room temperature, and then produces larger cohesiveness. It can be resistant to high temperature $\left(500^{\circ} \mathrm{C}-600^{\circ} \mathrm{C}\right)$, does not release ammonia or other harmful gases during the gel curing, has low cost and pollution-free. This paper mainly studies the influence of matrix content on the friction material characteristics. According to the properties analysis and experimental research of the friction material that produced by industries, choose the matrix content which is $16 \%-25 \%$ for the research, the formulation constituent of experimental group is shown in the Table $\mathbf{1}$. In the Table $\mathbf{1}$, the total mass of the formula is variable. In order to compare easily, this study supposes that keep the other parameters relatively unchanged except the matrix of the first column in the experiment. Use the fourth group as a benchmark, the total mass is 100 , and the content of various components is shown in the table. Keep the other parameters of the other groups unchanged in the experiment, and just change the matrix value. So, the data of the table is a reference value.

\section{Experimental Results and Analysis}

\subsection{Influence of Matrix on the Friction and Wear Properties of Friction Material}

The friction and wear properties of four kinds of formulated products were tested with the X-DM friction tester. Use induction to reorganize the experimental data. The test results are shown in the Tables 2 and 3. First, do the warming experiments, running 5000 revolutions at each temperature; then do the cooling experiments, running 5000 revolutions at each temperature similarly. The data of each group at the first line is for the warming, and the data of the second line is for the cooling.

It is difficult to observe the law of the data through the Tables 2 and 3. So using the data to generate the Figures $\mathbf{1}$ and 2, it is easy to observe its changing trend. Each kind of properties data are in 3 tests, the average of six pieces of friction plates.

It can be seen from the Figures $\mathbf{1}$ and $\mathbf{2}$ that the friction coefficient of the plates which were got from the experimental group1 is not stable. With the rise of temperature, the friction coefficient changed greatly, and at the same time the wear rate also changed bigger. This is because that the little content of the matrix and the lack of curing degree caused the friction material badly worn. With the increase of the matrix content, the plates of group 2 tended to be stable, the friction coefficient declined obviously, changed steadily. This is because that
Table 1. Material composition of matrix single factor experiment.

\begin{tabular}{cccccc}
\hline & $\begin{array}{c}\text { New Inorganic } \\
\text { Water-Based } \\
\text { Binder (\%) }\end{array}$ & $\begin{array}{c}\text { Reinforcing } \\
\text { Fibres (\%) }\end{array}$ & $\begin{array}{c}\text { Reduced } \\
\text { Iron Powder } \\
(\%)\end{array}$ & $\begin{array}{c}\text { Graphite } \\
(\%)\end{array}$ & $\begin{array}{c}\text { Other } \\
\text { Packing } \\
(\%)\end{array}$ \\
\hline 1 & 16 & 32 & 17.2 & 15.4 & 10.4 \\
2 & 19 & 32 & 17.2 & 15.4 & 10.4 \\
3 & 22 & 32 & 17.2 & 15.4 & 10.4 \\
4 & 25 & 32 & 17.2 & 15.4 & 10.4 \\
\hline
\end{tabular}

Table 2. Influence of matrix content on the friction coefficient.

\begin{tabular}{ccccccc}
\hline & \multicolumn{6}{c}{ Friction Coefficient $\mu$} \\
\cline { 2 - 7 } 1 & $100^{\circ} \mathrm{C}$ & $150^{\circ} \mathrm{C}$ & $200^{\circ} \mathrm{C}$ & $250^{\circ} \mathrm{C}$ & $300^{\circ} \mathrm{C}$ & $350^{\circ} \mathrm{C}$ \\
\hline \multirow{2}{*}{1} & 0.38 & 0.44 & 0.62 & 0.6 & 0.58 & 0.56 \\
& 0.65 & 0.65 & 0.63 & 0.57 & 0.58 & \\
\multirow{2}{*}{2} & 0.36 & 0.37 & 0.38 & 0.38 & 0.39 & 0.41 \\
& 0.42 & 0.43 & 0.42 & 0.41 & 0.44 & \\
\multirow{2}{*}{3} & 0.37 & 0.34 & 0.45 & 0.58 & 0.56 & 0.54 \\
& 0.4 & 0.39 & 0.46 & 0.50 & 0.57 & \\
\multirow{2}{*}{4} & 0.4 & 0.41 & 0.49 & 0.57 & 0.54 & 0.55 \\
& 0.47 & 0.40 & 0.55 & 0.61 & 0.54 & \\
\hline
\end{tabular}

Table 3. Influence of matrix content on the friction factor.

\begin{tabular}{ccccccc}
\hline \multirow{2}{*}{$\begin{array}{c}\text { Experimental } \\
\text { Group }\end{array}$} & \multicolumn{6}{c}{ Wear Rate $\mathrm{v}\left(\times 10^{-7} \mathrm{~cm}^{3} / \mathrm{Nm}\right)$} \\
\cline { 2 - 7 } & $100^{\circ} \mathrm{C}$ & $150^{\circ} \mathrm{C}$ & $200^{\circ} \mathrm{C}$ & $250^{\circ} \mathrm{C}$ & $300^{\circ} \mathrm{C}$ & $350^{\circ} \mathrm{C}$ \\
\hline 1 & 0.3 & 0.46 & 0.68 & 1.12 & 1.42 & 1.71 \\
2 & 0.24 & 0.31 & 0.53 & 0.71 & 0.79 & 1.02 \\
3 & 0.35 & 0.34 & 0.56 & 1.09 & 1.34 & 1.62 \\
4 & 0.42 & 0.51 & 0.80 & 1.34 & 1.62 & 2.1 \\
\hline
\end{tabular}

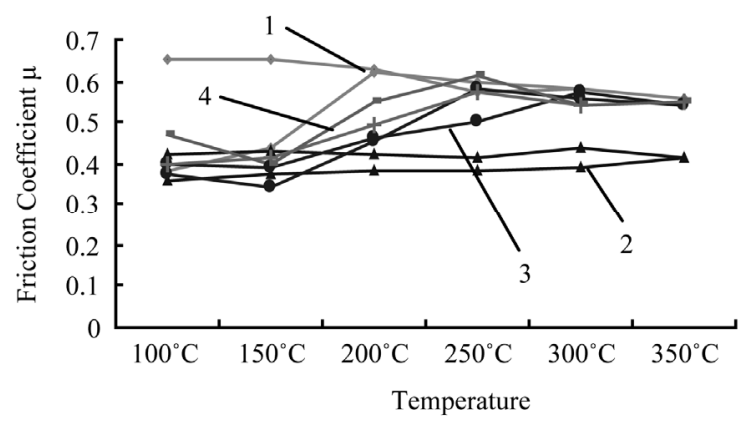

Figure 1. Influence of matrix content on the friction coefficient.

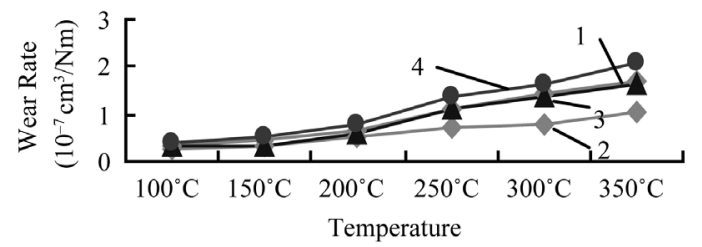

Figure 2. Influence of matrix content on the friction factor. 
with the increase of the matrix content the curing degree increased, then caused the compactness of friction material increased. The friction coefficient of the plates of group 3 and group 4 were biggish, the changes were especially obvious, the fluctuation of the wear rate is large in high temperature stage, and its stability is poor. Although the increase of matrix would cause the curing degree increases, it would make the inner pore of the plates increase in the process of drying and evaporation because the matrix contains lots of water. These would make the structure of friction material loose and the properties of friction material appear unstable phenomenon.

In summary, in the process of the matrix content changing from $16 \%$ to $19 \%$, the friction coefficient tended to be stable, heat fade is smaller, but the wear rate decreased significantly and changed steadily; When the content changing from $19 \%$ to $22 \%$, or even $25 \%$, it is obvious that the changes of the friction coefficient tended to be unstable, the fluctuation range was bigger and bigger, a definite heat fade phenomenon appeared, but the wear rate increased significantly, especially in the last high temperature stage it became unstable in the process. This shows that the friction and wear properties of friction material is better when the matrix content is about $19 \%$, it controlled the heat fade of the traditional friction material effectively.

\subsection{Influence of Matrix on the Impact Strength of Friction Material}

According to the assay method of the impact strength of friction material (GB5765-86), tested four groups of plates with the XCJ-4 impact strength tester. The test results are shown in the Tables 2-4.

In order to be intuitive, use the data of the table to generate the Figure 3.

It can be seen from the Figure 3 that the impact strength of friction material appears the trend that increases first and then decreases with the matrix content increasing. When the matrix content is $16 \%$, the curing degree of binder is low in the pressing process, the fiber springs back seriously after the pressure loss, it makes the structure of friction plates loose, so the lower impact

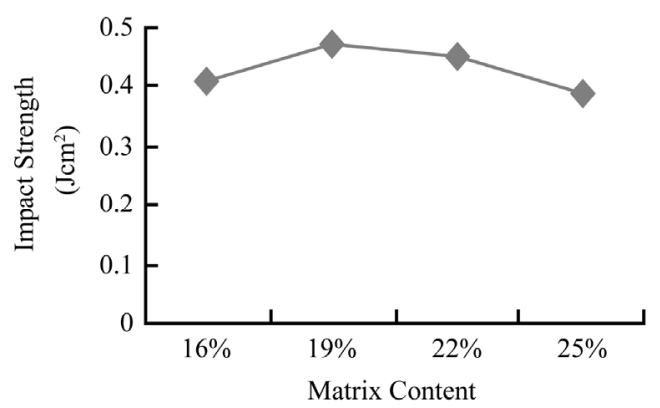

Figure 3. Influence of matrix content on the impact strength.
Table 4. Results of impact strength test.

\begin{tabular}{ccccc}
\hline Experimental Group & 1 & 2 & 3 & 4 \\
\hline Impact Strength $\left(\mathrm{J} \cdot \mathrm{cm}^{-2}\right)$ & 0.41 & 0.47 & 0.45 & 0.39 \\
\hline
\end{tabular}

strength is shown. With the rise of matrix content, the curing degree of binder is also enhanced, the fiber springs back difficultly after the pressure loss, the inner pore of the plates is less, the structure compactness of the plates increases, and the impact strength also increases. When the matrix content is $22 \%$ or even more, the curing degree of binder increases, but in the process of drying and evaporation lots of water that the matrix contains produces large water vapor, it would lead to the inner pore of the plates increases and the structure of friction material loose, the impact strength decreases gradually.

\section{Conclusion}

The influence of matrix content on the properties of friction material is composed of the following respects. The bonding strength which can influence the friction material: the more matrix, the better cohesiveness, but its friction characteristics highlight the matrix, the matrix can't be too much. Because of the water-based materials contains large water, it is easy to produce pore, the excessive matrix would lead to the pore get larger, influence the friction properties, especially the strength and wear resistance. The content of the new inorganic water-based binder which is used in this paper is appropriate about $19 \%$, in this case, the curing degree of binder is appropriate, and the friction and wear properties of friction material is the best.

\section{REFERENCES}

[1] S. W. Zhang, "Development State of British Friction Material without Asbestos and Its Test Specimen,” Proceedings of Friction Material, Vol. 10, 1999, pp. 29-38.

[2] R. Q. Xu and Q. Hu, "Study on the Friction and Wear of Cold Pressed Disk Brake Pad,” Tribology, Vol. 3, No. 9, 1998, pp. 259-262.

[3] J. L. Ye, "Preliminary Discussion the Ten Year's Practice of Cold-Press One-Step Forming Technology," China Asbestos Specimens, Vol. 3, 2001, pp. 22-25.

[4] Y. J. Zhang and Y. Q. Hu, "Property Comparison between Cold-Press and Hot-Press Clutch Friction Material," Non-Metallic Mines, Vol. 28, No. 2, 2005, pp. 51-53.

[5] R. J. Lu and Y. Q. Hu, "Cold-Press Process of Friction Materials with Two-Component Resin," Materials for Mechanical Engineering, Vol. 27, No. 8, 2003, pp. 34-37.

[6] Y. Yu and Y. Q. Hu, "Warm-Press Process of Brake Friction Materials,” Non-Metallic Mines, Vol. 28, No. 1, 2005, pp. 50-52.

[7] T. Zhu and Y. Q. Hu, "Research on Warm-press Process 
of Clutch Friction Material,” Non-Metallic Mines, Vol. 2, No. 3, 2006, pp. 58-60.

[8] J. F. Wei and Y. Q. Hu, "Preparation of Drum Brake Friction Materials by Warm-Press Process,” Non-Metallic
Mines, Vol. 2, No. 3, 2007, pp. 59-61.

[9] Q. W. Qu, J. X. Wan and L. J. Fu, "Research on the New Type of Heat-Fading-Resistance Friction Materials," $L u$ brication Engineering, Vol. 33, No. 2, 2008, pp. 104-105. 